\title{
Analysis on Different Levels of Sharing Finance
}

\author{
Wei Liping \\ Weifang University \\ Weifang, Shandong Province, China
}

\begin{abstract}
Finance sharing is a finance model of the new era which is characterized by resource sharing, factor sharing and benefit sharing, representing the concept of shared development among the five major development concepts-innovation, coordination, ecology, openness and sharing. The most basic and primary goal finance sharing holds is to improve living conditions. Therefore, the primary level of sharing is to solve financial availability. The theme of shared finance is to promote sharing of reform achievements through financial development. Therefore, the next level of sharing is to solve long-term financial repression of China. In the new era, reducing income distribution GDP is required by finance sharing. Therefore, the third level of sharing is to solve the unbalanced financial development in China. The levels of sharing finance show that the policies of a country in the financial development should be considered comprehensively, and gradually, to ensure the realization of shared essence of sharing finance.
\end{abstract}

Keywords-sharing finance, financial availability, financial repression, income distribution GDP

\section{INTRODUCTION}

The five concepts about development- "innovation, coordination, ecology, openness and sharing" were put forward in the Fifth Plenary Session of the 18th CPC Central Committee and sharing is an overall goal which enables common people to gain more in the process of shared development and heads towards common prosperity. As the widespread application of the shared economy model represented by Uber taxi and Airbnb rental, the concept of "shared finance" gradually permeates into the economic and financial fields which is a very humane concept originally, and has also been born with great attention and wide support from all walks of life. Therefore, As modern financialization develops in a rapid way, shared economy has been constantly developed from traditional sharing economy and network sharing economy. In September 2015, Yao Yundong, director of the Institute of Finance of the People's Bank of China, put forward the concept of "shared finance" for the first time in "China's Top 50 People Shared Finance Forums.” Domestic scholars began to carry out multiple researches on nature, characteristics, advantages and problems confronted by finance sharing.

Shared finance is not just a concept of innovation, but a brand-new financial industry, which has in common with the ideal inclusive finance, the previous hot internet finance, but the connotation of shared finance is more rich and more promising. Shared finance and internet finance are both born in order to meet the optimal allocation of resources, but shared finance also has public welfare considerations in addition to profitability, paying more attention to win-win and sharing mechanism, expanding the breadth and depth of inclusive financial services. It can be said that internet finance is the specific manifestation of the shared finance in the current special historical stage. The rapid development of internet technology has produced internet finance, but it only highlights the technical characteristics, and does not reveal the essential characteristics of internet era finance. In contrast, shared finance based on the prosperity and development of shared economy can reflect the deep change of financial model, so shared finance should have a longer life than internet finance.

This paper argues that finance sharing is not only innovation of financial concepts based on inclusive finance and the Internet, but a financial model of the new era featuring resource sharing, factor sharing and benefit sharing. Finance sharing can be understood from three aspects, namely, improving living conditions, promoting sharing of reform achievements and narrowing income distribution gap through financial development.

\section{THE ROLE OF IMPROVING THE LIVING CONDITIONS WITH FINANCIAL DEVELOPMENT}

The first level of finance sharing, that is, the most basic level, is to improve human conditions. In this sense, the firstlevel of finance sharing is actually financial availability. Some scholars in China have carried out researches on financial availability from the theoretical and empirical aspects. For example, Yin Zhichao et al. argues in his article entitled "Financial Availability, Financial Market Participation and Choice of Family Assets" that increasing financial availability can make families more involved in asset allocation of formal financial markets to reduce the informal financial market activity and the proportion of private lending. It will bring marginal impact on greater participation in the formal financial market of families in rural and Midwest areas. We can conclude that demand and supply, macro environment contribute to financial availability as a problem. From the demand side, those who need financial services may not be able to access services due to geographical or physical constraints, or do not know whether they have qualification to get service due to basis and shortage of documented materials, or even lack of their basic costs. From the perspective of supply, too high threshold of traditional financial services sector and single type of traditional financial products are the main reasons why certain people are excluded from the financial system. From environmental factor, no matter financial "hardware" facilities such as financial institutions, financial terminals, payment and settlement systems, or 
financial "software" facilities such as the financial legal system, credit system and consumer protection system are obviously not covered in specific regions and specific groups of people. In particular, it needs to be pointed out that according to China's national situation, the focus of inclusive finance is not only the central and western regions and the vast rural areas, but people living in the "vast middle belts" of the central and eastern areas and those enterprises between medium-sized and large enterprises also have the phenomenon of insufficient financial services.

Most developing countries are now aware that the problem of financial availability is the "last mile" problem, namely, the financial availability problem is mainly caused by inadequate financial infrastructure. Many countries have introduced targeted solutions: on the one hand, to strengthen the construction of financial infrastructure; On the other hand, vigorously develop digital inclusive finance. It should be recognized that the "last mile" is a comprehensive issue, and that there are many other measures beyond financial infrastructure that need to be followed up, such as innovative financial products, deepening financial services, innovative business philosophy, etc.. In the face of the flourishing development of a new set of inclusive financial models represented by internet finance, an effective measure to solve financial availability is to improve inclusive finance, especially the modern digital inclusive finance. This is an important starting point for achieving the sharing of financial resources, and also a goal and means. Because digital inclusive finance is a product of the integration of concept of universal benefits and modern Internet technologies, it can break up the last mile of financial services and provide relatively fair opportunities of shared financial services to the population in impoverished areas and people in the "middle zone". At the same time, we must guide the rise and development of online finance seriously and correctly and create a new modern platform for financing SMEs and individuals. In short, making all people without access to formal financial services opportunities to get adequate financial services is the most fundamental goal of sharing ideas through financial development.[1]

\section{THE ROLE OF PROMOTING THE SHARING OF REFORM ACHIEVEMENTS WITH FINANCIAL DEVELOPMENT}

Since the implementation of reform and opening up policy, China's average annual growth rate is about $10 \%$, becoming a miracle in the history of economic development at home and abroad. To promote the sharing of reform achievements with financial development should be the theme of shared finance. However, China's investment and export-oriented economic growth model is at the cost of financial repression characterized by low interest rates, high inflation, strong credit rationing, devaluation of the local currency and capital controls. As a result, development benefits are more brought to the government than residents.

According to statistics from the World Bank, since China's reform and opening up, the contribution rate of investment to GDP has been basically between $35 \%$ and $50 \%$ per annum. However, during this period, the average consumption rate of residents has risen less than $50 \%$, not even the basic level of developing countries. As a result, a large number of products brought by huge productivity are digested through exports and domestic income is converted into savings-type investment at low consumption. Therefore, China has also become one of the largest depositors in the world in the same period. The key point is that the source of high investment funds in China for more than 30 years are mainly from bank loans. The bank loans carried out in China are fixed-rate policies, and sometimes the real interest rates are even zero or negative, as shown in the Fig. 1 below[2] .

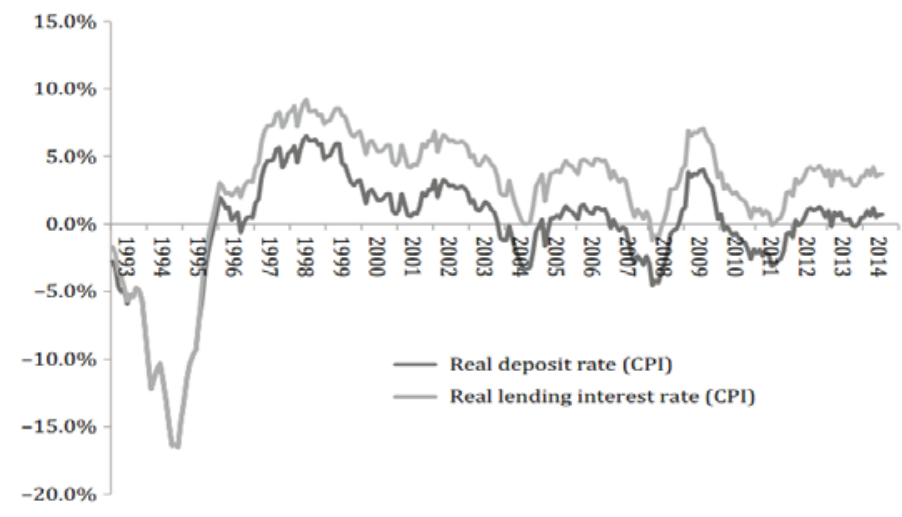

Fig. 1. True interest rate from 1993 to 2014 in China

Therefore, profits gained by the government and stateowned enterprises come first from so-called interest margin. That is, the financial sector moves huge financial surpluses from residents and non-public sectors at prices far below the equilibrium market rate at the state's discretion, and then are lent to key state-owned enterprises with far less than market average interest rates. At the same time, with the rigidity of other domestic investment projects and international capital controls as the guarantee, the government can maintain longterm interest margin. As a result, financial repression has robbed the rich and the poor of related interest groups like a water pipe. Yin Heguo et al. pointed out in "Political Economics of Financial Repression in China" that from 2000 to 2009, the proportion of Chinese residents' income in the initial distribution of national income dropped from $51.4 \%$ to $42.8 \%$ and the proportion of redistribution increased from $64.8 \%$ to $54.3 \%$, well below the proportion of $70 \%$ of U.S. income of national income.[3]

Financial repression not only makes it impossible for fruits of financial development to be shared by all, but has caused the expansion of total social investment and drastically reduced the efficiency of capital utilization. Since enterprises, especially state-owned large enterprises, have state credit as a guarantee for their loans, they do not have to worry about the profitability of their enterprises. They put main focus on loanseeking loans, resulting in an ever-increasing scale of loans and a continuous decline in the production efficiency of enterprises. "State-owned enterprises exist the loss of efficiency itself, and because of soft budget constraints, it drags down the progress of private-owned enterprises, which limit the growth of the entire economy."[4] According to statistics from China's National Development and Reform Commission, China's incremental capital output in 2009-2013 was averagely 4.2 , significantly higher than the 3.3 in the previous two decades and higher than the worldwide average 
of 3 in the same period. This shows that China's Return on investment is on the decline. Under the financial repression, the means where the government and the state-owned enterprises gain intangible subsidies is not unique, except for interest rate rent and benefit from currency issuance. For more than 30 years of reform and opening up, especially since 2002, the speed of money issuance in China has far exceeded the rate of economic growth, even the rate of economic growth plus the inflation and the necessary monetary reserves. The central bank can buy treasury bonds, or make currency hedging for foreign currency purchases, or issue additional currency to expand their loans. The interest rate difference between the assets and debtors formed through the currency issuance will result in money issuance proceeds, which are turned into the central government's financial profit. Over the same period, residents suffered the loss of profits brought by inflation due to the large-scale rapid growth of the amount of money. If financial repression aimed to subsidize it that the state-owned enterprises and the finance department shouldered the cost for the stability of the initial reform and the state, the subjective and objective conditions for the present "stabilizers" have undergone a fundamental change. In the crucial period of the financial reform, to ensure the sharing nature of finance sharing, key points are: to prevent "path dependence" of financial repression; "collective action dilemma" of "non-public clique"; and reforms without any progress due to unfair resources.

If financial repression aimed to subsidize it that the stateowned enterprises and the finance department shouldered the cost for the stability of the initial reform and the state, the subjective and objective conditions for the present "stabilizers" have undergone a fundamental change. To reduce financial repression is a necessary choice for our country to shift its approach in the new normal period and to adjust its structure to promote sustainable economic development, but also a necessary requirement for deepening the development of finance to realize a comprehensive financial sharing. In the crucial period of the financial reform, to ensure the sharing nature of finance sharing, key points are: to prevent "path dependence" of financial repression; "collective action dilemma" of "non-public clique"; and reforms without any progress due to unfair resources.

\section{THE ROLE OF NARROWING THE INCOME DISTRIBUTION GDP WITH FINANCIAL DEVELOPMENT}

According to a report published by World Bank in 2010, $5 \%$ of the population in the United States has $60 \%$ of the nation's wealth while $1 \%$ of China's families have mastered $41.1 \%$ of wealth, which becomes one of the countries with the worst imbalances in the world's income distribution.[5] Another proof is as shown in the figure below:

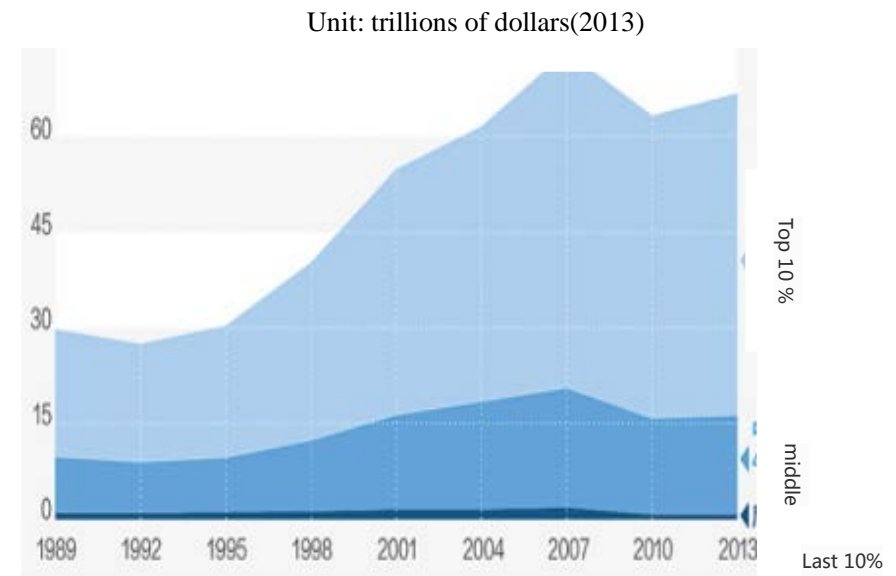

Fig. 2. Gap Between Rich and Poor in the United States (1989 - 2013)

However, as the GDP of China's income distribution becomes bigger, it is also a period of rapid economic and financial development. Therefore, the issue on the correlation between financial development and income distribution has drawn great attention from scholars. There always been three views on the study of relationship between financial development and income distribution. The first theory is that financial development will reduce the income GDP. The theory holds that in the process of financial development, reducing financial costs can narrow the GDP between rich and poor. The second theory is that financial development will expand the income GDP. Because of different human capital investment, financial development will expand income distribution. The third theory is the non-linear relationship between financial development and income distribution pattern, such as the inverted U-shaped hypothesis of Greenwood and Jovanovic (1990). From research results most scholars published in China, the financial development in China clearly shows trends and symptoms that lead to the worsening of income distribution GDP. From a macro point of view, the unbalanced development of finance has widened the income GDP between urban and rural areas. Especially since the 1990s, when the reform of financial market-oriented reforms started, a large number of state-owned banks merged their branches from rural areas, leading to long-term rural capital outflows. Unbalanced distribution of financial resources in urban and rural areas and urban financial expansion has made rural economic efficiency further reduced.

At the same time, financial resources are rich in China's eastern coastal region and its expansion speed far outperforms the central and western regions under the self-expansion effect, which contributes to more economic efficiency and affects the income growth of residents through the marginal output of labor, and thus further widens the income disparity between Eastern and Central and Western Regions. From a microcosmic point of view, China has a single channel for financial services. Low-income earners can only obtain lowincome deposits and currency. High- income earners can thus obtain longer-term high yields through stocks, bonds and funds. Especially in rural areas, since the 1990s, cost of the financial services is much higher, widening the GDP between urban and rural areas. Education resources and education 
quality in China's urban and rural areas are significant different. In addition, with differences in the flow of talent, making the return on human capital investment exists a huge difference; from credit exposure channels, large enterprises and high-quality private-owned enterprises are more likely to get bank loans while small and micro-enterprises and residents find it hard to dispel moral risk. From labor market, small and medium-sized and micro-sized enterprises have obtained a very small amount of loans while employing more than $80 \%$ of employed workers, but it is not conducive to technological improvements and raising of wages of workers.[6]

Financial development is featured by "hate the poor and love the rich" and "add ice on the cake", so it only makes the development gains benefit a few people, which obviously runs counter to the concept of finance sharing. In the long run, we must expand the coverage of financial services in rural areas to reduce the income GDP between urban and rural areas. We must optimize financial system arrangements to promote competition in the financial industry to solve loans for small, medium and micro-sized enterprises and the general public. A well-functioning capital market should be established to enable businesses and residents to diversify their investment channels. The financial support for vulnerable groups should be improved. Reform of the financial reform and other economic systems can be carried out to correct inequality in the financial development.

\section{CONCLUSION}

Under the background of the times and the convergence of the light of thought, the concept of shared finance coincides with the central concept of shared development. From shared economy to shared finance, and then to shared development, the concept has a far-reaching impact in the continuous extension. The concept of shared development not only leads the development direction of shared finance in the future, but also points out the value orientation of China 's social development, maintains social fairness and justice, ensures that the development results are shared by the people, and lays a foundation for realizing the goal of building a well-off society in an all-round way and promoting sustained and healthy economic and social development.

In a word, sharing finance is not only a new financial format, but also a modern evolution of traditional functions of finance. The levels of sharing finance show that the policies of a country in the financial development should be considered comprehensively, and gradually, to ensure the realization of shared essence of sharing finance.

\section{REFERENCES}

[1] Liu Shunping. Developing Digital Inclusive Finance and Enhancing the Effectiveness of Anti-poverty. Gansu Finance, May,2017.

[2] Paul Armstrong-Taylor. Debt and Distortion. Macmillan Publishers Ltd. London, September, 2016.

[3] Wei Liping. On the Nature and Causes of the New Normalization of the Polarization between the Rich and the Poor. Marxism Research, luly, 2015.

[4] Liu Ruiming, Shi lei. Double Efficiency Loss and Economic Growth of State-owned Enterprises. Economic Research, January 1,2010.

[5] Fang Wenquan. Empirical Study on Determinants of Labor Income share in China: Structural Adjustment or Financial Effect. Financial Research, February 15, 2011.

[6] Gan Li, Yin Zhichao, Jia Nan, Xu Shu, Ma Shu. A Financial Survey about China Family 2015. Southwestern University of Finance and Economics Press, 2015. 